\title{
Program for Calculating Optimal Diet Therapy in Children With Hereditary Enzymopathy (cystic fibrosis)
}

\author{
Kruchkova A.V. \\ Voronezh State Medical University n.a. N.N. Burdenko, Voronezh, Russia \\ *Corresponding author. Email: lusha8722@yendex.ru
}

Ulyanova L.V.* Ledneva V.S. Chertok E.D. Talykova M.I. Korchagina N.S.

\begin{abstract}
Nutritional malnutrition or protein-energy deficiency (PED) remains a problem in treating patients with a hereditary pancreatic enzyme deficiency (cystic fibrosis). A software product has been developed for assessing the degree of PED of children with cystic fibrosis and calculating an optimal diet therapy. During the dynamic observation and application of the diet using the calculation program in 37 patients with cystic fibrosis positive dynamics of physical development parameters was obtained, according to body mass index, transferrin level and the absolute number of leukocytes, which allowed normalizing the trophological status of patients. After three years of using this option for calculating diet therapy, a severe degree of PED was not detected in any patient. The average degree of PED was determined in 3 patients (10\%), mild in $17 \%$ and $73 \%$ of patients had a normal state of nutrition. Computer program " Integrated assessment system of proteinenergy deficiency and the calculation of the optimal diet for children suffering from cystic fibrosis" allows calculation of the optimal menu for patients suffering from cystic fibrosis makes it possible to draw up the correct individual diet with the determination of the degree of PED and ensure stable improving the parameters of the physical development of patients.
\end{abstract}

\section{Keywords: cystic fibrosis, diet therapy, individual diet, Hereditary Enzymopathy}

\section{INTRODUCTION}

Chronic diseases affect negatively to nutritional status that reduces the effectiveness of therapy, increases the duration of the patient's stay in the hospital and risk of an unfavourable prognosis. There are a few studies dedicated to nutritional therapy for children with cystic fibrosis (CF) that have scientific substantiation and proven effectiveness. Moreover, they relate mainly to use of foreign enteral correction products. Protein-energy deficiency (PED) is a serious problem for patient suffering $\mathrm{CF}$ negatively affecting the outcome of therapy. Diet for a child with cystic fibrosis should contain high-calorie foods and likes to the normal composition as much as possible. Diet should be rich in proteins without limiting the amount of fat and should include available products [1-3].

Creating an individual menu allows achieving normalization of nutritional status in many patients $[4,5]$.

Nutritional status assessment in CF-patients is necessary for early diagnosis of its disorder as well as choosing the right strategy for nutritional therapy and dynamic monitoring of its effectiveness. The determination of the caloric content of the diet and PED severity is very difficult for outpatient paediatrician. This was the reason for the creation of special software product named as "Integrated assessment system of protein-energy deficiency and the calculation of the optimal diet for children suffering from cystic fibrosis". The wide range of software for automating the process of preparing a diet is currently available on the market. Presented software have a number of advantages such as implementing a balanced menu based on calories, proteins, fat, micronutrients and vitamins quantity. This kind of software allows composing "technological maps" and recipes. However, the most software is intended for use in the preschools, schools and medical preventive institutions. All this programmes allow ensuring a rational nutrition in groups of children according to general diets but not be used for patients with severe genetic pathology such as cystic fibrosis.

The purpose of our work was the creation of special software for nutrition status assessment and calculation of adequate nutrition therapy for children with genetic enzyme deficiency.

\section{MATERIALS AND METHODS}

According to the balanced diet theory, normal functioning of the body is possible only in receiving an adequate amount of energy. The amount of receiving energy should correspond to the actual dailyenergy waste. The actual daily energy waste (AEW) consists of the basic metabolism (BM) and specific dynamic action of food (SDAF) taking into account physical activity, gender and 
age. In this connection the actual daily energy waste in patient with $\mathrm{CF}$ was calculated using the formula:

$\mathrm{AEW}=\mathrm{BM} \times \mathrm{SF}+\mathrm{MCI}$,

where AEW - the actual daily energy waste, BM - basic metabolism (kkal/day), SF - stress factor, MCI metabolic correction index (kkal/day).

Stress factor in children with $\mathrm{CF}$ was estimated depending on the period of disease:

- $\mathrm{SF}=1.0-$ absence of exacerbation

- $\mathrm{SF}=1.2-$ exacerbation by type of bronchitis

- $\quad \mathrm{SF}=1.3-$ exacerbation by type of pneumonia

- $\mathrm{SF}=1.6-$ complications in the form of the systemic generalized inflammation.

Metabolic correction index was calculated using the formula:

$\mathrm{MCI}=\mathrm{AF}+\mathrm{TF}+\mathrm{SDAF}+\mathrm{WG}$

where $\mathrm{AF}$ - activity factor (kkal/day), $\mathrm{TF}$ - thermal factor (kkal/day), SDAF - specific-dynamic action of food (kkal/day), WG - weight gain (kkal/day). Thermal factor is defined as $10 \%$ of the basic metabolism on every $100 \mathrm{C}$ of average daily body temperature increase. Specificdynamic action of food means basic metabolism increase due to various food components intake. Specific-dynamic action of food for children was calculated using the formula:

$\mathrm{SDAF}=0.1 \times \mathrm{BM}$.

Weight gain depends on the child gender: from 1 to 4 years $-\mathrm{WG}=63 \mathrm{kkal} / \mathrm{day}$; from 5 to 13 years $-\mathrm{WG}=32$ $\mathrm{kkal} /$ day; from 14 to 16 years $-\mathrm{WG}=113 \mathrm{kkal} / \mathrm{day}$. Basic metabolism is a minimum amount of energy that is required for life support in a state of complete rest. Basic metabolism was calculated using the Harris-Benedict's formula:

$\mathrm{BM}($ for boys $)=66.5+(13.7 \times \mathrm{W})+(5.0 \times \mathrm{H})-6.8 \times \mathrm{n}$ $\mathrm{BM}$ (for girls $)=66.5+(9.5 \times \mathrm{W})+(1.8 \times \mathrm{H})-4.7 \times \mathrm{n}$, where BM - basic metabolism, W - weight $(\mathrm{kg}), \mathrm{H}-$ height $(\mathrm{cm}), \mathrm{n}-$ age (years).

Harris-Benedict's formula was based on creating the computer program with which we could calculate the adequate menu for patient suffering of CF. We used the information database about food products (and dishes made from them) with a certain energy value according to the Institute of Nutrition of Russian Academy of Medical Sciences Clinical Recommendations for this patient's category.

The use of this software had a significant benefit when we determined the PED degree and made a choice of diet therapy. Effectiveness of the individual diet was monitored in 37 patients with $\mathrm{CF}$ during the year.

Patients were monitored in hospital and in out-patient hospitals too. We performed a control of physical, functional and laboratory parameters every week and added it to database. Also we determined the necessary correction of diet therapy.

We used successfully the Bilberry-Cohen's method for determine the degree of PED [6]. Firstly we filled to the program some parameters such as patient's weight $(\mathrm{kg})$, height $(\mathrm{cm})$, thickness of the skin-fat fold over the triceps $(\mathrm{mm})$ and shoulder circumference $(\mathrm{mm})$. Then we determined the level of the basic metabolism parameters and added the information of patient's current nutrition condition that was evaluated in balls. After that we received a result of actual daily energy necessity calculation.

Some laboratory investigations were performed such as serum transferrin, protein, albumin, absolute levels of leucocytes and lymphocytes.

Well-known that decrease transferrin level is one of the marks of protein deficiency due to its short lifetime ( 8 days). The grade of protein deficiency can be evaluated easily according to the transferring dynamics level. Also it can help to identify the patients with high rick of severe nutrition deficiency and prevent it. Serum transferrin level as well as protein and albumin level measurements were performed with chemistry device «Liasys S-67».

Absolute leucocytes and lymphocytes counting is screening method for evaluation of immune system function and also can be used for identification of patient's protein-energy condition. Lymphocytes absolute level was calculated using the traditional formula:

Lymphocytes (x 109/1) =

= Lymphocytes (\%) x Leucocytes (x 109/l) / 100.

This investigation was performed using the haematological analyser «Sysmex XI-1800 15-4».

Process of patients' nutritional status investigation and food ration creation was started from the anamnesis collection and physical examination. The fact of the diagnosis of $\mathrm{CF}$ establishment as well as form, severity and period of disease were clarified during the conversation with the patient and his parents. The following indicators for determining energy requirements were recorded: age, gender, activity factor and stress factor. Activity factor was determined according to patient's activity - bed rest, home rest or sitting in a chair. Stress factor has depended on patient's condition exacerbation presents or absence, type of the exacerbation, presents of septic process.

Than physician performed weight, height and temperature measurements. All information was filled to appropriate field in program screen. This data was used for evaluation of therapy effectiveness and it correction. Developed information system included a number of modules: module for calculating current values of nutritional patient status indicators; the module for comparison current data with the standard and interpretation of the results; module for calculation diet therapy.

Preparation of the daily menu was carried out according to principle that daily caloric content of the diet is the same or more of actual daily energy requirement.

The following formula reflects this condition: DCC $\geq$ DR (condition1), where DCC - daily caloric content of the diet, DR - actual daily energy requirement. After drafting an individual daily diet calculation of it calorific was performed and fulfilling the condition 1 was checked .The diet can be recommended to the patient if the condition 1 
is met. Considering the fact that the diet for a week should be various, the presented algorithm was repeated for every day of the week with the same baseline data but other meal. Thus, the result of a physician's consultation was the provision of individual recommendations on the patient's diet for a week.

\section{DISCUSSION OF RESULTS}

Diet therapy for MB-patients involves high-protein and high-calorie feeding without limitation of fat. The adequate enzyme replacement therapy as well as additional administration of fat-soluble vitamins must be provided at the same time [6-9]. There are no products or dishes that would be prohibited for the patient suffering from CF. The main rule of diet therapy for this disease is the active personalized approach to the patient nutrition at any age.

Feeding should be regular -6 times per day (even for school children) according the formula $3+3$. It means 3 basic feeding (breakfast, lunch, dinner) and 3 additional snacks (second breakfast, afternoon snack and snack before night.) Food should be plentiful enough - each main meal should include dishes containing high-quality animal proteins (meat, fish, eggs, cheese and cottage cheese). In addition, the food should be rich in highquality fats - vegetable oil (rapeseed, soy, linseed, pumpkin, olive, sunflower and corn), butter, cream, sour cream. The carbohydrates should include both complex (cereals, bread, vegetables) and non-complex carbohydrates (sweets, jam, honey). Additional meals should consist of fermented milk products, cottage cheese, fruits, cookies and moderate amount of sweets.

In bronchopulmonary exacerbations and the significant delay in weight the specialized high-energy cocktails or the artificial milk formulas for enteral nutrition are recommended to use. Indication for additional nutrition with specialized high-energy formula is any reducing body weight/height gain and actual body weight below the 25 th percentile $[8,9]$.

The main objective of our research was to organize the optimal individual nutrition system for patients suffering from $\mathrm{CF}$ according to the requirements of modern nutrition.

37 patients suffering from $\mathrm{CF}$ were examined according to protocol during 3 years. The average age of patients was $5.83 \pm 1.39$ year. All patients were divided into three subgroups considering the age. The first subgroup includes preschoolers (children from 3 to 6 years), the second younger schoolchild (from 7 to 9 years) and the third subgroup - high school children (from 10 to 15 years).

After entering the patient's data, the program performed the calculation of actual energy consumed per day and PED grade. For making an individual diet of the patient with $\mathrm{CF}$ we used the sections of the daily menu (breakfast, lunch, afternoon snack, dinner). Each of section includes list of meals with indication of the portion weight, caloric content, protein, fat and carbohydrates quantity. After the doctor has selected a specific diet the program calculated its daily energy value as well as protein, fat and carbohydrates content. It allowed evaluating the compliance of the created dietary recommendations with the proper parameters of nutritional support. If this necessary condition is met than the program confirmed the correctness of the choice diets "The menu is correct" title appeared on the screen. Only after that the physician prescribed a calculated diet for the patient. The program made a conclusion «The menu should be corrected" if the selected diet did not comply with the mandatory condition. To change the diet, the doctor checked the daily menu sections consistently and changed the diet variants. Similar actions were repeated until the program confirmed the correctness of the newly created menu. During the 3 years of dynamic observation and using this program all 37 patients achieved positive dynamics of physical growth parameters, serum transferrin level and absolute number of leucocytes (Table 1).

Table 1 Dynamics of physical development parameters and laboratory data in children with CF using software calculation diet therapy

\begin{tabular}{|l|l|l|}
\hline $\begin{array}{l}\text { Trophic status } \\
\text { parameter } \\
(\mathbf{n = 3 7})\end{array}$ & $\begin{array}{l}\text { Initial } \\
\text { average } \\
\text { value of the } \\
\text { parameter }\end{array}$ & $\begin{array}{l}\text { The average } \\
\text { value of the } \\
\text { parameter after } \\
\mathbf{3 6} \text { months of } \\
\text { diet therapy }\end{array}$ \\
\hline $\begin{array}{l}\text { Body mass } \\
\text { index, kg/cm }\end{array}$ & $\begin{array}{c}19.62 \\
(\mathrm{p}<0.05)\end{array}$ & $21.31(\mathrm{p}<0.05)$ \\
\hline $\begin{array}{l}\text { Transferrin, } \\
\text { mg/dl }\end{array}$ & $\begin{array}{l}185.1 \\
(\mathrm{p}<0.05)\end{array}$ & $201.8(\mathrm{p}<0.05)$ \\
\hline $\begin{array}{l}\text { Absolute number } \\
\text { of leucocytes, } \\
109 / 1\end{array}$ & $2.87(\mathrm{p}<0.05)$ & $3.54(\mathrm{p}<0.05)$ \\
\hline
\end{tabular}

The analysis of average BMI dynamics in patients who received individual correct diet therapy have shown that the most intense BMI increase was in the third age subgroup (children from 10 to 15 years). This result can be explained by higher compliance in this subgroup.

The parameter of absolute number of leucocytes also had a positive dynamic in all patients with the most intensively increasing in the second patient's subgroup. It is interesting that maximum increase in the number of white blood cells was registered between the first and the second years of treatment.

The transferring level increased significantly any without difference in subgroups that is the evidence of reduced inflammation.

Based on this data it is possible to confirm that immunological protection in children with $\mathrm{CF}$ improved significantly after diet therapy course. The results of study showed that grade of PED also reduced significantly (Table 2). 
Table 2 Dynamics of PED grade after individual diet therapy.

\begin{tabular}{|c|c|c|c|c|}
\hline PED grade & Normal & I & II & III \\
\hline $\begin{array}{c}\text { Before diet } \\
\text { therapy (\%) }\end{array}$ & 0 & 76 & 20 & 4 \\
\hline $\begin{array}{c}\text { After diet } \\
\text { therapy (\%) }\end{array}$ & $\begin{array}{c}73 \\
(\mathrm{p}<0.05)\end{array}$ & $\begin{array}{c}17 \\
(\mathrm{p}<0.05)\end{array}$ & $\begin{array}{c}10 \\
(\mathrm{p}<0.05)\end{array}$ & $\begin{array}{c}0 \\
(\mathrm{p}<0.05)\end{array}$ \\
\hline
\end{tabular}

\section{CONCLUSION}

Suggested software product "Integrated assessment system of protein-energy deficiency and the calculation of the optimal diet for children suffering from cystic fibrosis" allows realizing the calculating of optimal menu for patients with congenital enzymes deficiency. This method is based on the principles of a personalized approach to the patient. The program's functionality includes the following: individual comprehensive monitoring of physical health (weight, height, BMI), assessment of the adequacy of the diet, choosing an algorithm for nutritional and enzyme correction, calculation of enzyme therapy based on dietary fat consumption and data storage and systematization. Created software product for calculating diet therapy in patient with CF allows making a correct individual diet according to protein-energy deficiency grade and ensuring stable improvement of patient's physical development parameters. The software product can be recommended for the daily practice of paediatricians and nutritionist.

\section{REFERENCES}

[1] A.V. Orlov (ed.), Medical issues and problems of adolescents with cystic fibrosis, Methodical recommendation, St. Petersburg, 2017, 160 p.
[2] R.F. Tepaev, T.E. Borovic, K.S. Ladodo, Parenteral nutrition in pediatrics and pediatric surgery, Clinical dietology of children's age: Guideline for physitions, 2rd ed., Med. inform. agency, Moscow, 2015, pp. 557-573.

[3] S.J. Schwarzenberg, S.E. Hempstead, C.M. McDonald et. al., Enteral tube feeding for individuals with cystic fibrosis: Cystic Fibrosis Foundation evidence-informed guidelines, J. of Cystic Fibrosis 15 (2016) 724-735.

[4] L.V. Ulyanova, V.N. Ivleva, Correction of trophic disorders in children suffering from cystic fibrosis, Quest. of Childr. Dietet. 6 (2014) 14-19.

[5] L.V. Ulyanova, V.N. Ivleva, A.N. Ivlev, Program Comprehensive system for evaluating protein-energy failures and the calculation of the optimal diet for children suffering from cystic fibrosis, Certificate of registration of an electronic resource vol. 19966, no. 50201450200, date of publ. 05.03.2014.

[6] G.L. Bilbrey, T.L. Cohen, Identification and treatment of protein calorie malnutrition in chronic hemodialysis patients, Dialy sis Transplant. 18 (1989) 669-677.

[7] D. Turck, C.P. Braegger, C. Colombo et al., Espenespghan guidelines on nutrition care for infants, children and adults with cystic fibrosis, Clin. Nutrition 35 (2016) 557-577.

[8] S.J. Schwarzenberg, S.E. Hempstead, C.M. McDonald, S.W. Powers, J. Wooldridge et al., Enteral tube feeding for individuals with cystic fibrosis: Cystic Fibrosis Foundation evidenceinformed guidelines, J. of Cystic Fibrosis 15 (2016) 724-735.

[9] A. Morton, S. Wolfe, Enteral tube feeding for cystic fibrosis, Cochrane Database of Syst. Rev. 4 (2015) CD001198. DOI: 10.1002/14651858.CD001198.pub4 